\title{
Spatio-temporal variability in Mediterranean rocky shore microphytobenthos
}

\author{
E. Maggi ${ }^{1,2, *}$, L. Rindi ${ }^{1,2}$, M. Dal Bello ${ }^{1,2,5}$, D. Fontanini ${ }^{3}$, A. Capocchi ${ }^{3}$, L. Bongiorni ${ }^{4}$, \\ L. Benedetti-Cecchi ${ }^{1,2}$ \\ ${ }^{1}$ Dipartimento di Biologia, Università di Pisa, Via Derna 1, 56126 Pisa, Italy \\ ${ }^{2}$ CoNISMa, Consorzio Nazionale Interuniversitario per le Scienze del Mare, 00196 Rome, Italy \\ ${ }^{3}$ Dipartimento di Biologia, Università di Pisa, Via L. Ghini 13, 56126 Pisa, Italy \\ ${ }^{4}$ Istituto di Scienze Marine - Consiglio Nazionale delle Ricerche (ISMAR-CNR), Arsenale - Tesa 104, Castello 2737/F, \\ 30122 Venezia, Italy \\ ${ }^{5}$ Present address: Massachusetts Institute of Technology, 77 Massachusetts Avenue, Cambridge, MA 02139, USA
}

\begin{abstract}
Knowledge of spatio-temporal variability of assemblages is the first step in identifying key factors affecting the abundance and distribution of organisms. Despite a long history of ecological studies on rocky intertidal habitats, there is still a lack of basic knowledge about the microphytobenthic components. We investigated the spatio-temporal variability of microphytobenthos in the northwest Mediterranean at multiple scales, including both seasonal and daily observations, as well as its composition. Spatial variability of microphytobenthic biomass varied significantly with season, with an increase in small-scale variance from cold to warm periods. Furthermore, during warmer months, small-scale variances (tens to hundreds of centimeters) were larger than large-scale components (tens to thousands of meters). These results suggest large spatio-temporal variation in the processes driving variation in microphytobenthic assemblages, including interactive effects among stressful abiotic conditions, substratum topography and grazing. In addition, observed variability on a daily scale suggested that microphytobenthos at the study site (dominated by cyanobacteria) might cope with stressful environmental conditions through both physiological and behavioral strategies at micro-spatial scales, including small movements within the substratum. Additional research on ecological and physiological aspects of rocky shore microphytobenthos is needed to better understand its role within interaction webs and primary productivity processes.
\end{abstract}

KEY WORDS: Spatio-temporal variability $\cdot$ Microphytobenthos $\cdot$ Daily variation $\cdot$ Bacterial diversity $\cdot$ Rocky shore $\cdot$ Mediterranean Sea

\section{INTRODUCTION}

Studies of spatial and temporal scales of variability in population abundance and distribution have provided insights into scale-dependent patterns of many terrestrial and aquatic assemblages, and represent a starting point for the identification of underlying causes (Underwood \& Chapman 1996). Intertidal rocky shores are among the most investigated mar-

${ }^{*}$ Corresponding author: emaggi@biologia.unipi.it ine habitats in ecological studies and there is extensive knowledge of the spatial and temporal variability of the organisms that inhabit them, such as macroalgae and invertebrates (e.g. Underwood \& Chapman 1996, Menconi et al. 1999, Benedetti-Cecchi 2001, Blanchette et al. 2006, Martins et al. 2008, Burrows et al. 2009, Dal Bello et al. 2017a). A comprehensive knowledge of the variability of rocky intertidal assemblages, however, is still lacking,

() The authors 2017. Open Access under Creative Commons by Attribution Licence. Use, distribution and reproduction are unrestricted. Authors and original publication must be credited. 
mainly due to a scarcity of ecological studies on microscopic components, compared with macroscopic ones.

Our knowledge of rocky shore microorganisms is mainly confined to epilithic microphytobenthos (hereafter EMPB), whose variability has been historically investigated along the rocky shores of Great Britain, Australia and Hong Kong. Such studies have highlighted that EMPB abundance is usually greater lower on the shore than higher (Castenholz 1963, Underwood 1984, Dye \& White 1991, Jackson et al. 2010), and in winter than in summer (Underwood 1984, Jenkins \& Hartnoll 2001, Williams et al. 2001; but see Jackson et al. 2010). In the Mediterranean, a recent study compared spatial patterns of EMPB at scales ranging from 0 to $2 \mathrm{~m}$ apart and showed that biomass distribution is scale-invariant (Dal Bello et al. 2015). However, these studies concentrated on a limited range of spatial scales and focused mostly on seasonal patterns, neglecting other potentially important scales of temporal variability. In addition, spatial and temporal patterns have been mostly examined separately, thus precluding the possibility of investigating spatio-temporal interactions and the underlying causes (Underwood \& Petraitis 1993).

Finally, although there is a wide literature on daily and tidal vertical migrations of diatoms in sandy or muddy habitats, we still have very limited understanding of the patterns of daily variability of EMPB on hard substrata. Rocky shores are usually considered as 2-dimensional spaces, so macroscopic organisms are classified as sessile or motile over the rock surface. However, in some cases, such as for calcareous rocks, a 3-dimensional habitat is conceivable, at least for boring organisms such as EMPB (Naylor et al. 2012). Marine euendolithic cyanobacteria, as an example, can penetrate calcareous substrata by actively boring them and/or colonizing existing spaces within the rock (Golubic 1969). In addition, the synthesis of extracellular polysaccharides (EPS) by both diatoms and cyanobacteria (Underwood et al. 1995, Smith \& Underwood 1998, Potts 1999) could help these organisms to move within the first few millimeters of the rock surface, possibly as a behavioral defense mechanism against desiccation or UV radiation during periods of high irradiance.

The lack of information on many aspects of EMPB variability is at odds with the important ecological roles played by these organisms on rocky shores. The EMPB provides food for many grazing invertebrates (such as gastropods and amphipods; e.g. Underwood 1978, Christofoletti et al. 2011, Sanz-Lázaro et al. 2015) and facilitates the settlement of algal propag- ules and invertebrate larvae $\left(\mathrm{O}^{\prime}\right.$ Connor \& Richardson 1998, Huang \& Hadfield 2003). In addition, relatively recent studies have shown that some invertebrates (namely littorinids and barnacles) can in turn positively affect EMPB biomass through facilitation mechanisms (Skov et al. 2010, Maggi et al. 2015), suggesting that interaction webs involving EMPB are complex. Deepening our knowledge of spatio-temporal variability of these organisms is an important and rarely accomplished step toward the identification of factors affecting major primary producers of rocky shore habitats. At the same time, it will help reveal the underlying causes and mechanisms of variations in ecological processes that rely on the development of EMPB biofilms, such as feeding behavior and settlement of marine organisms.

We applied a hierarchical sampling design to investigate seasonal variations in the spatial variance components of EMPB biomass over a 30 mo period, encompassing scales from a few centimeters to several kilometers, in the northwest Mediterranean. We expected a greater variability at small spatial scales if biotic interactions as well as small-scale physical processes played a key role in shaping EMPB assemblages (e.g. Benedetti-Cecchi 2001, Fraschetti et al. 2005); greater variance was expected at larger spatial scales if assemblages were mostly shaped by physical processes acting at relatively large scales, such as shoreline geomorphology or currents (e.g. Jenkins et al. 2000, Broitman \& Kinlan 2006). On a daily scale, we predicted a temporal decrease in EMPB biomass, due to behavioral and physiological defense mechanisms against increasing irradiance and desiccation or UV radiation.

EMPB assemblages were characterized by identifying major microalgal pigment groups and by scanning electron microscopy (SEM). Since both these analyses revealed the dominance of cyanobacteria in the EMPB, we carried out a further detailed investigation on the diversity of the whole bacterial component (i.e. including both autotrophic and heterotrophic organisms) using high-throughput sequencing of 16S rRNA genes (Taylor et al. 2014)

\section{MATERIALS AND METHODS}

\section{Study location}

Sampling was conducted in a micro-tidal system, between 0.2 and $0.4 \mathrm{~m}$ above the mean low water level, along a sandstone rocky shore about $3.5 \mathrm{~km}$ long in the northwest Mediterranean (south of Li- 
vorno, Italy; $\left.43^{\circ} 47^{\prime} \mathrm{N}, 10^{\circ} 33^{\prime} \mathrm{E}\right)$. Due to the limited amplitude of tides, barometric pressure is the primary force determining the position of the sea level in this environment. In particular, assemblages at this height are usually above the sea level; they are wetted only by wave-splashes occurring during sea storms. At this height on the shore, assemblages were characterized by small patches of encrusting barnacles, mostly Chthamalus stellatus (Poli), separated by apparently bare rock colonized by EMPB. The most common grazer was the littorinid snail Melaraphe neritoides (Linnè).

\section{Seasonal variability of EMPB biomass}

We repeatedly sampled EMPB biomass nondestructively at 2 randomly chosen sites $(50 \mathrm{~m}$ long and hundreds of meters apart) within each of 2 random localities $3 \mathrm{~km}$ apart (Calafuria and Calignaia, which are similar in rock composition, wind and wave exposure, as well as macroscopic assemblages). On 8 dates between March 2012 and September 2014, 3 randomly chosen plots $(52 \times 35 \mathrm{~cm})$ were photographed at each site using an infrared-sensitive camera (ADC). While the same localities and sites were repeatedly sampled, different plots were randomly chosen on each date. As a proxy for EMPB biomass, we used chlorophyll a (chl a) values estimated from a ratio vegetational index (RVI), calculated for each of 6 replicate regions of interest (ROIs: $3 \times 3 \mathrm{~cm}$ ) in each plot, by processing data through a java-routine in the ImageJ program (see Dal Bello et al. 2015 for further details). On each date, sampling was carried out between 08:30 and 10:30 h (local time) under comparable conditions (i.e. sunny day and calm sea). Dates were representative of 2 distinct seasonal periods, characterized by warm (end of August-end of September; 'warm' season, 4 dates) or relatively cold (end of February-beginning of May; 'cold' season, 4 dates) air and water sea temperatures, during which EMPB biomass encompassed a large range of values (from 0.018 to $8.35 \mu \mathrm{g} \mathrm{chl} \mathrm{a} \mathrm{cm}^{-2}$ ). Despite initial sampling plans, cold and warm dates were not sampled in the same year, resulting in temporally segregated sampling (cold dates: 14 March and 10 May 2012, 28 February and 25 April 2013; warm dates: 23 August and 26 September 2013, 3 and 26 September 2014).

Seasonal variability in EMPB biomass values was estimated using a multifactorial ANOVA. The full model included 5 factors: 'season' (fixed, 2 levels, cold vs. warm), 'date' (random, 4 levels, nested within 'season'), 'locality' (random, 2 levels, crossed with 'season' and 'date'), 'site' (random, 2 levels, nested within 'locality' and crossed with 'season' and 'date') and 'plot' (random, 3 levels, nested within the interaction 'site' $\times$ ('date'('season')). As the main objective of the analysis was to test for seasonal variability in EMPB biomass, we simplified the spatial structure of the model to obtain a denominator for testing the main factor of interest ('season'). In particular, we ran a 4-way ANOVA by eliminating the factor 'locality' and including the factor 'site' with 4 levels. It is worth noting that analysis of the full model showed no significant seasonal variability in the effects of 'locality' or 'site' (data not shown).

Variance components were also extracted for each sampling date to quantify spatial variation at the scales of centimeters (among ROIs), meters (among plots), hundreds of meters (between sites) and kilometers (between localities). Variance components were then analyzed with a 2-way ANOVA, with 'season' (2 levels, warm and cold) and 'spatial scale' (4 levels, locality, site, plot and ROI) as fixed, crossed factors $(n=4)$. When significant effects were detected, the Student-Newman-Keuls (SNK) test was used for a posteriori comparisons of the means (Winer 1971, Underwood 1997). Homogeneity of variances was tested using Cochran's test. When heterogeneity could not be removed through transformation of data, significance of $F$ test (type I error) was set at $\mathrm{p}<0.01$.

\section{Daily variability of EMPB biomass}

To test the hypothesis of daily changes in EMPB biomass, on 3 sunny days during the cold season (16 March and 11 May 2012, 17 April 2014), we repeatedly photographed 4 randomly chosen plots $(52 \times$ $35 \mathrm{~cm}$ ) at each of 2 randomly chosen sites at Calafuria. Different plots were chosen on each date. Photographs were taken at regular intervals of $1 \mathrm{~h}$ and 50 min during the day, starting at 10:30 h (T1) and finishing at 16:00 $\mathrm{h}(\mathrm{T} 4)$. At each of the 4 time points, we sampled the same 6 circular ROIs (area $=9 \mathrm{~cm}^{2}$ ), randomly chosen at $\mathrm{T} 1$ (their perimeters were drawn with a white chalk to facilitate their subsequent location). EMPB biomass was estimated as previously described (Dal Bello et al. 2015).

To deal with temporal autocorrelation (i.e. ROIs, plots and sites repeatedly sampled through time), values of EMPB biomass were analyzed using a mixed-effects model (MEM; Singer \& Willet 2003), with 'plot' and 'site' as nested random effects. Time was included in the fixed part of the model, due to $a$ priori expectations about a decrease in EMPB bio- 
mass with increasing irradiance or desiccation stress. To test for alternative decreasing patterns, time was included either as a linear or quadratic term. Selection of the best model (given the data) with respect to specific choices of temporal structure was based on the lowest Akaike's information criterion (AIC) value. Fixed and random components within the MEM were estimated through maximum likelihood (ML) and restricted maximum likelihood (REML), respectively (Singer \& Willet 2003). Homogeneity of variances and normality in the residual distributions were visually checked.

ANOVA and the MEM were run using the GAD and lme4 packages, respectively; models were compared using the ANOVA function (R v2.15.3, R Development Core Team 2013).

\section{Identification of microalgal pigments and EMPB scanning electron microscopy observations}

Reverse-phase high-performance liquid chromatography (RP-HPLC) was used to identify major pigment groups from rock chips randomly taken at Calafuria in February and July 2013. After collection, the chips were frozen at $-80^{\circ} \mathrm{C}$. Rock chips were then extracted overnight at $-30^{\circ} \mathrm{C}$ with $95 \%$ cold methanol containing $2 \%$ tetra-butyl ammonium acetate (TBAA). The extract was then centrifuged at $7500 \times g$ for $10 \mathrm{~min}$ at $10^{\circ} \mathrm{C}$, aliquoted and stored in liquid nitrogen. The chromatographic separation was based on our modification of the method by Van Heukelem \& Thomas (2001). An aliquot of extract was mixed with 28 mM TBAA, pH 5.5 (3:1). Then, $500 \mathrm{\mu l}$ of this mixture was injected onto a C8 column (Eclipse XDB, $4.6 \times 150 \mathrm{~mm}, 3.5 \mu \mathrm{m}$ ) equilibrated with $90 \%$ solvent $\mathrm{A}$ and $10 \%$ solvent $\mathrm{B}$ (solvent $\mathrm{A}$ : methanol added with $28 \mathrm{mM}$ TBAA, pH 5.5, 70:30; solvent B: $100 \%$ methanol). Separation was achieved at $60^{\circ} \mathrm{C}$ with a linear gradient from $10 \%$ to $95 \%$ B in $35 \mathrm{~min}$, followed by a $7 \mathrm{~min}$ step at $95 \%$ B (flow rate: $1 \mathrm{ml} \mathrm{m^{-1 }}$ ). Elution was monitored at $430 \mathrm{~nm}$ using a 996 PDA detector (Waters) and analyzed by the Millennium chromatography software (Waters). A set of pigment standards (mixed pigments; DHI) was also separated under the aforementioned conditions. Single peaks collected from repeated injections were adsorbed on STRATA-XL (Phenomenex) columns and eluted with acetone. Eluents were then concentrated 4 times under a nitrogen stream and their spectra acquired between 350 and $750 \mathrm{~nm}$ with a dual beam UV-visible Lambda 25 spectrophotometer (Perkin-Elmer). Due to the small amount of pigments obtained in February by analyzing each chip separately, samples collected in July were analyzed all together.

Additional small chips of rock taken in July 2013 were fixed in $2.5 \%$ glutharaldehyde $\left(2 \mathrm{~h}\right.$ at $\left.4^{\circ} \mathrm{C}\right)$, then dehydrated through 7 steps (15 min each) in ethylic alcohol at increasing concentrations (from 30 to $100 \%$ ) and finally desiccated through critical point drying (Balzers Union CPD 020). The surface of samples was covered with a thin gold leaf $(\sim 10 \mathrm{~nm})$ (sputter coating; Edwards Sputter Coater S150B) and observed under a scanning electron microscope (SEM Jeol JSN-5410).

\section{Diversity of epilithic bacteria based on16S rRNA gene amplicon sequencing}

Samples were randomly collected at 3 intertidal sites located 10-30 m apart at Calafuria (hereafter indicated as Sites S1, S2 and S3) in September 2015 (warm period). Replicated rock chips ( $\mathrm{n}=8$, mean surface area of approximately $30 \mathrm{~cm}^{2}$ each) were collected using a sterile chisel and hammer, placed in sterile jars and kept frozen until further analyses. In the lab, biofilms were carefully scraped from the entire surface of each rock chip using a sterile razor blade. Biofilm DNA was extracted using the PowerSoil DNA isolation kit (MO-BIO Laboratories). Bacterial 16S rRNA amplicon libraries were generated by polymerase chain reaction (PCR) amplifications of the V4 variable region of the 16S rRNA gene. PCRs were carried out in $18 \mu \mathrm{l}$ reaction mixture containing $8 \mu \mathrm{l}$ of $2.5 \times 5$-Prime HotMasterMix, $0.4 \mu \mathrm{l}$ of $3 \mathrm{mM}$ BSA, $1 \mu \mathrm{l}$ of $1 \times$ EvaGreen fluorescent dye and $1.3 \mu \mathrm{l}$ $(0.4 \mu \mathrm{M})$ of the forward primer $515 \mathrm{~F}\left(\mathrm{~S}^{-}{ }^{*}-\mathrm{Univ}-0515-\right.$ a-S-19: GTGCCAGCMGCCGCGGTAA-3') (Caporaso et al. 2012) and a mix of the reverse primers 806R (S-D-Bact-0787-b-A-20, 5'-GGACTACHVGGG TWTCTAAT-3') (Caporaso et al. 2012) and 802R (SD-Bact-0785-b-A-18, 5'-TACNVGGGTATCTAATCC$3^{\prime}$ (Claesson et al. 2009). PCR conditions were $94^{\circ} \mathrm{C}$ for 2 min followed by 30 cycles of $94^{\circ} \mathrm{C}$ for $20 \mathrm{~s}, 52^{\circ} \mathrm{C}$ for $20 \mathrm{~s}$ and $65^{\circ} \mathrm{C}$ for $40 \mathrm{~s}$, and a final elongation step at $65^{\circ} \mathrm{C}$ for $2 \mathrm{~min}$. Each of the 8 amplicons obtained in this way was tagged with a barcode sequence and successively combined with the other samples in equimolar ratios, purified on gel and precipitated with ethanol to remove any remaining contaminants and PCR artifacts. Sequencing of the rock chips' amplicon library was carried out on the Ion Torrent PGM (Life Technologies) system using the Ion PGM $^{\mathrm{TM}}$ Hi- $\mathrm{Q}^{\mathrm{TM}}$ View Sequencing Kit (Life Technolo- 
gies) on an Ion 316 chip v2 (Life Technologies) in accordance with the manufacturer's instructions. The QIIME (Caporaso et al. 2010) software package was used to process the raw sequence data. Short $(<200 \mathrm{bp})$ ambiguous and low-quality reads (average phred score $<20$ ) were removed. Open operational taxonomic units (OTUs) were defined at $97 \%$ similarity and classified against the Greengenes reference database (version 13_8) (DeSantis et al. 2006) using open reference (Rideout et al. 2014) with a UCLUST clustering tool (Edgar 2010). Chimeric sequences were identified against the Greengenes reference database using ChimeraSlayer (Haas et al. 2011) and excluded. Before further analysis, singletons, archeal and chloroplast plastid sequences were removed from the dataset and samples were checked for sequencing depth. Rarefaction analysis was done for Chao1 and Shannon diversity indices, Faith's phylogenetic diversity and number of observed OTUs to assess alpha diversity, while beta diversity was assessed with weighted and unweighted UNIFRAC distance matrices (Lozupone \& Knight 2005, Lozupone et al. 2006) and visualized with Emperor (Vázquez-Baeza et al. 2013) 3-dimensional principal coordinates analysis plots.

\section{RESULTS}

\section{Seasonal variability of EMPB biomass}

Mean EMPB biomass showed no seasonal trend, but there were significant differences among dates, with higher values for the last 2 warm sampling occasions (Table 1, Fig. 1). The significant interaction between 'plot' and 'date' (Table 1) highlighted a pattern of higher variability among plots during the warm season compared with the cold season (28/48 vs. $12 / 48$ significant SNK contrasts). The ANOVA components revealed a significant interaction between 'season' and 'scale' $\left(F_{\text {SEASON }} \times\right.$ SCALE $=$ 5.147, $\mathrm{p}<0.01$ ). SNK tests showed a significant increase in spatial variance of EMPB biomass from cold to warm seasons at spatial scales of centimeters (among ROIs) to meters (among plots), as well as a significant difference among spatial scales during the warm season (plot $=$ ROI $>$ locality $=$ site) (Fig. 2) .

\section{Daily variability of EMPB biomass}

EMPB biomass showed a general decreasing pattern on a daily scale, but with variable temporal trends among sampling dates (Table 2). In particular, on Day 1 (16 March 2012), the results showed a significant negative second-order temporal parameter, due to a decrease in biomass values after the first $2 \mathrm{~h}$ since the start of the sampling (Fig. 3A). On Day 2 (11 May 2012), both linear and quadratic terms were significant, but with opposite signs compared with the previous sampling date. This was due to a sharp decrease in biomass values during the first $6 \mathrm{~h}$ and an

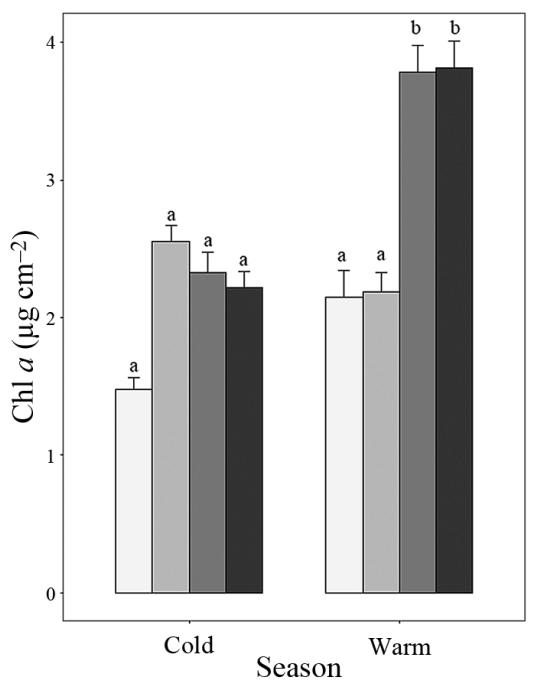

Fig. 1. Mean epilithic microphytobenthos biomass (+1 SE, $\mathrm{n}=72$ ) on 4 random dates (bars of different colors) within cold and warm seasons. Data collected between March 2012 and September 2014. Different letters indicate significantly different means according to SNK tests 


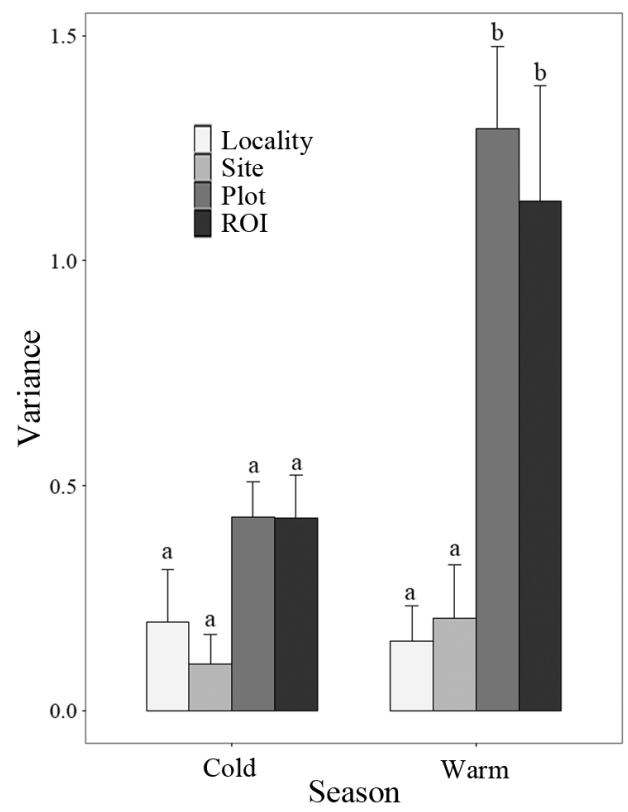

Fig. 2. Mean variances (+1 SE) of epilithic microphytobenthos biomass at the scales of centimeters (ROI: region of interest), meters (plot), hundreds of meters (site) and several kilometers (locality) during cold and warm seasons. Different letters indicate significantly different means according to SKN tests

increasing trend between 14:00 and 16:00 h (Fig. 3B). On Day 3 (17 April 2014), data were best modeled through a linear, but not significant, temporal trend (Fig. 3C). Average air temperature differed among sampling dates, with a relatively high value on 11 May 2012 compared with the other 2 days (mean hourly temperature ( $\pm 1 \mathrm{SE}$ ) between 10:00 and 16:00 h at Livorno: 16 March $2012=14.8 \pm 0.2^{\circ} \mathrm{C}_{i} 11$ May $2012=21.7 \pm 0.3^{\circ} \mathrm{C}_{i} 17$ April $2014=16.6 \pm 0.2^{\circ} \mathrm{C}_{i}$ www.mareografico.it).

\section{Characterization of the epilithic microscopic community}

RP-HPLC analyses of the methanolic extracts of rock chips were comparable between February and August 2013 (Fig. 4; to improve clarity, for February we included the extract from one chip since the others showed similar peaks). They revealed the presence of the xanthophylls zeaxanthin and cantaxanthin, chl $a$ and $\beta$-carotene. These pigments were identified based on their co-elution with the corresponding standards (peaks a-d, respectively), and their spectral characteristics (Egeland 2011). Moreover, the spectral analyses of peaks 1-3 (Fig. 4) suggested the presence of scytonemin-like, myxoxanthophyll-like and echinenone-like pigments, respectively (Egeland 2011).

SEM analysis showed that the surface area of rock chips in August was covered mainly by a carpet of microbial filamentous forms, spherical microorganisms (ca. $2 \mu \mathrm{m}$ diameter) in lower abundances and irregular-shaped fragments consisting of detrital matter (Fig. 5). In contrast, fragments of diatoms were less frequently detected (data not shown).

Mass parallel sequencing of rock chips collected in September 2015 yielded a total of 225777 high-quality reads (i.e. sequences with non ambiguous nucleotides and/or with a length $>200 \mathrm{bp}$ ). Out of these, a total of 224498 reads were recognized as bacterial, after the removal of chloroplast and archaeal sequences. According to the Shannon diversity index $\left(H^{\prime}\right)$ and the observed number of OTUs, diversity of samples ranged between $H^{\prime}=5.7$ (1300 OTUs) and 6.8 (1515 OTUs), with the exception of one sample at Site S3 (S3_2), which was characterized by a highly
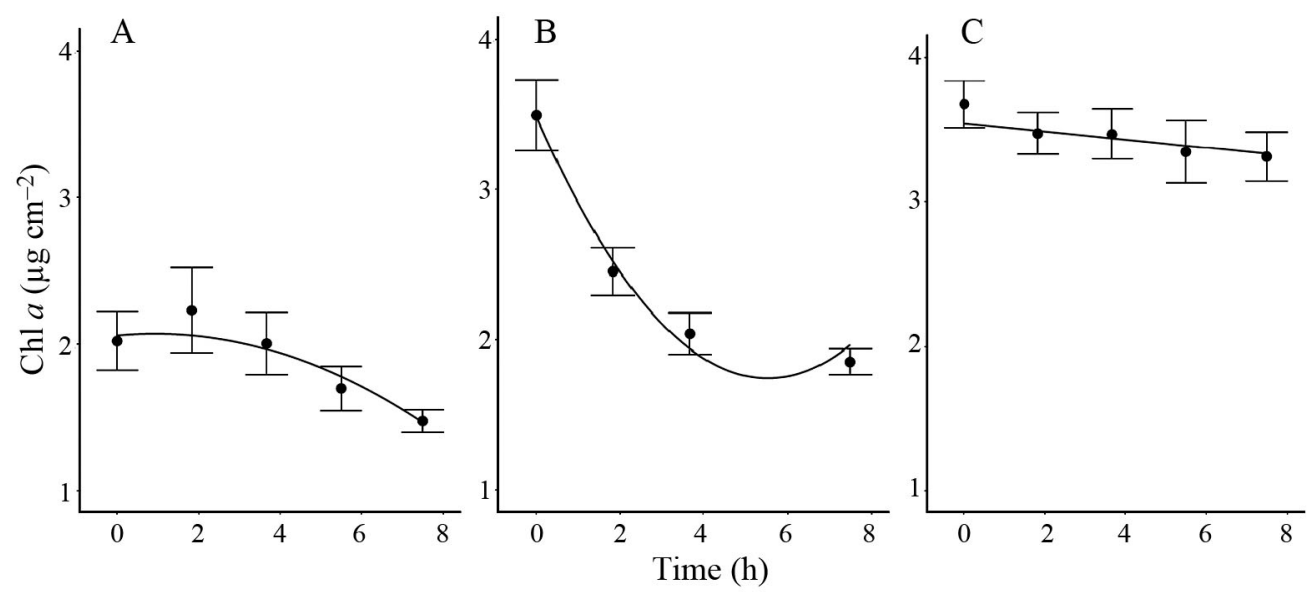

Fig. 3. Observed mean values (+1 SE) of epilithic microphytobenthos biomass during the day at about $1 \mathrm{~h} 50$ min intervals (from 10:30 to 16:00 h) on 3 sampling dates: (A) 16 March 2012, (B) 11 May 2012 and (C) 17 April 2014. Fitted temporal trajectories from the mixed-effects models are shown as black lines 


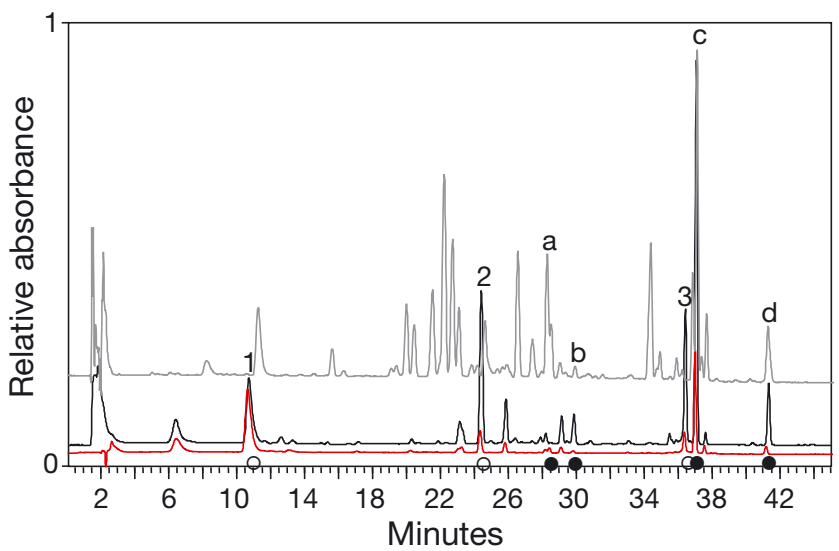

Fig. 4. Pigment identification by RP-HPLC analyses. Superimposed chromatograms of the methanolic extracts of rock chips (red line: February 2013, one chip, weight $=19.3 \mathrm{~g}$, area $\sim 3.14 \mathrm{~cm}^{2}$; black line: August 2013, all chips, weight = $104.05 \mathrm{~g}$, area $\sim 15.7 \mathrm{~cm}^{2}$ ) and pigment standards (gray line). Letters from a to d correspond to zeaxanthin, cantaxanthin, chlorophyll $a$ and $\beta$-carotene standard peaks, respectively; 1-3 refer to the tentatively identified scytonemin, myxoxanthophyll and echinenone, respectively

diverse community $\left(H^{\prime}=7.99,1851\right.$ OTUs). The epilithic bacterial community clustered in 3 main separate groups according to sampling area (data not shown), except for Sample S3_2, which appeared to be completely separate from the other rock chips.

Based on $97 \%$ similarity with Greengenes database, a total of 217 specific bacterial taxonomic groups were assigned. Despite variability among sampling areas, the epilithic bacterial community at the study site was dominated by the phyla Cyanobacteria (27.4$69.0 \%$ ), followed by Bacteroidetes (12.0-37.5\%), Proteobacteria (4.8-20.8\%) and Actinobateria (0.5-9.7\%, Fig. 6). The family Rivulariaceae dominated (Cyanobacteria, Nostocales, ranging between 1 and $51 \%$ of total bacterial OTUs), followed by the orders Chroococcales (Cyanobacteria, 12-30\%) and Cytophagales (Bacteroidetes, 4.5-19\% Fig. 6). Sample S3_2 showed higher relative abundances of Cytophagales (Bacteroidetes, 19\%), Sphingomonadales (Proteobacteria, 6\%) and the cyanobacteria Nostocales $(7.5 \%$, Fig. 6$)$, compared with all the other samples. Sample S3_2 was also the most diverse in terms of number of exclusive taxa, yielding $1.25 \%$ exclusive bacterial families.

\section{DISCUSSION}

The results highlighted a significant influence of season on spatial variability in EMPB biomass, with an increase in small-scale spatial variance from cold to warm seasons. During warmer months, small-scale variances (from centimeters to meters) were also larger than large-scale components (up to some kilometers). On a daily scale, the results showed variability among dates, but there was a general pattern of decreasing EMPB biomass with increasing irradiance or desiccation stress.

Except for chl a (common in other taxonomic groups), pigments identified by RP-HPLC analyses (i.e. zeaxanthin, cantaxanthin, $\beta$-carotene, echinenone, myxoxantophyll, scytonemin) revealed that cyanobacteria dominate at the study site during both the cold and warm seasons. This was supported by SEM analysis, which showed that multicellular filamentous forms, resembling branching cyanobacterial morphotypes in shape and size, dominate the high-shore rock surface in July. In contrast, other EMPB components, such as diatoms, were observed only in a few cases (photo not shown). Several previous studies have reported the dominance of the cyanobacteria components in biofilms under conditions of high desiccation, such as those occurring on tropical rocky shores (Nagarkar \& Williams 1999) or on temperate shores during summer (e.g. UK, Hill \& Hawkins 1991, Thompson et al. 2004, 2005). Temperate Mediterran-
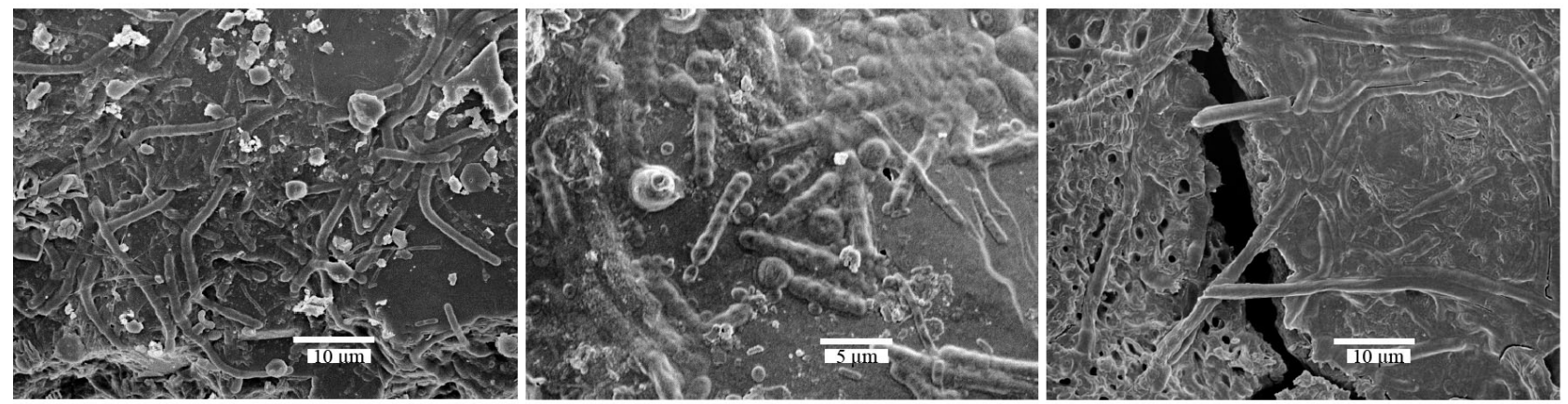

Fig. 5. Scanning electron micrographs showing the surface area of rock chips covered by filamentous bacteria, detrital matter and fragments of diatoms 


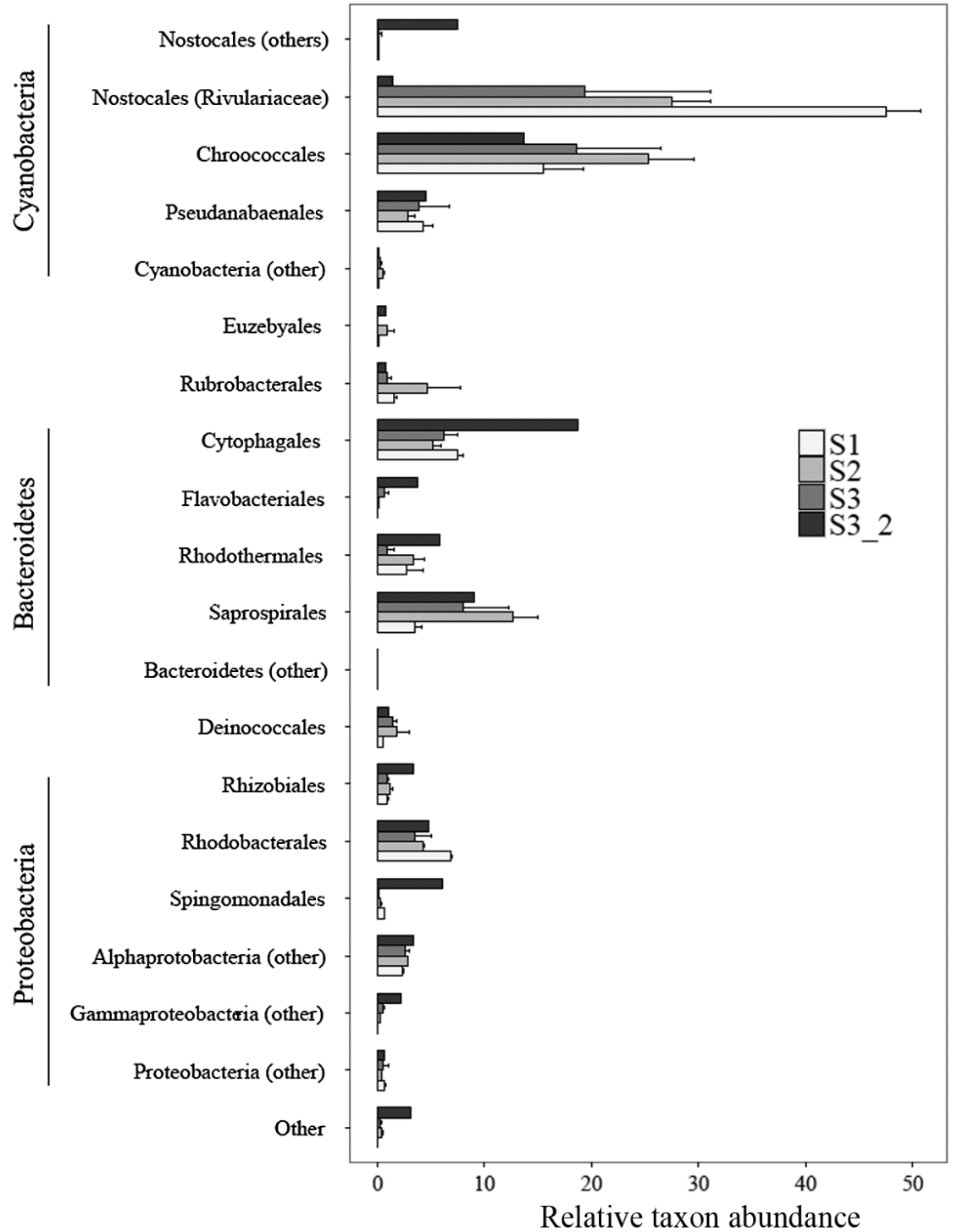

Table 2. Mixed-effects model results for short-time scale variability of epilithic microphytobenthos biomass (estimated as $\mu \mathrm{g}$ of $\mathrm{chl} \mathrm{a} \mathrm{cm}^{-2}$ ) on 3 different sunny days during the cold season. ${ }^{*} \mathrm{p}<0.05,{ }^{* * *} \mathrm{p}<0.001$. ROI: region of interest

\begin{tabular}{|lccc|}
\hline & $\begin{array}{c}\text { Day 1 } \\
\text { (16 March 2012) })\end{array}$ & $\begin{array}{c}\text { Day 2 } \\
\text { (11 May 2012) }\end{array}$ & $\begin{array}{c}\text { Day 3 } \\
\text { (17 April 2014) }\end{array}$ \\
\hline Fixed effects (coefficient + SE) & & & \\
Intercept & $2.057(0.228)^{* * *}$ & $3.482(0.212)^{* * *}$ & $3.541(0.243)^{* * *}$ \\
Time linear & $0.026(0.052)$ & $-0.63(0.072)^{* * *}$ & $-0.028(0.019)$ \\
Time quadratic & $-0.014(0.006)^{*}$ & $0.057(0.008)^{* * *}$ & \\
Random effects (variance) & & & \\
ROI (intercept) & 1.119 & 0.951 & 0.493 \\
ROI (time linear) & 0.246 & 0.308 & 0.049 \\
ROI (time quadratic) & 0.027 & 0.036 & 0.66 \\
Plot & 0.425 & 0.223 & 0.000 \\
Area & 0.000 & 0.252 & 0.559 \\
Residual & 0.356 & 0.366 & \\
\hline
\end{tabular}

Fig. 6. Epilithic bacterial community composition at the study site. Bars indicate relative taxon abundance (mean \pm SE) at order level (with the exception of the family Rivulariaceae) in the 3 plots. Sample S3_2 was kept separate from other samples to show differences

ean rocky coasts are extremely variable environments, due to the limited amplitude of tides. Changes in barometric pressure are the primary forces dictating the timing and duration of aerial exposure for sessile organisms, inducing abrupt fluctuations in thermal and desiccation conditions all year round, particularly in the high-shore habitat (Benedetti-Cecchi et al. 2006). Interestingly, Jackson et al. (2010) revealed that cyanobacteria dominate temperate sandstone shores around Sydney throughout the year. 
Together with macroalgal organisms, cyanobacteria are the most important primary producers on rocky coasts and are generally key players in the biogeochemical cycling of carbon and nutrients, along with heterotrophic microorganisms (Thompson et al. 2000, Magalhães et al. 2007). Despite their ecological importance, however, only a few studies have documented the diversity of the epilithic bacterial communities (e.g. Nagarkar \& Williams 1999, Ortega-Morales et al. 2005, LaScala-Gruenewald et al. 2016) and, to the best of our knowledge, only once by means of high-throughput sequencing of 16S rRNA genes (Taylor et al. 2014). At the study site, cyanobacteria clearly dominated the bacterial assemblage; in particular, during the warm period, the filamentous, heterocyst-forming genera Rivularia were by far the most abundant, reaching up to $50 \%$ of the whole bacterial assemblage (Fig. 6). It should be noted that the genus Rivularia, which belongs to the family Rivulariaceae, is classified according to the National Center for Biotechnology Information taxonomy and the revision of the order Stigonematales within the order Nostocales (also see Gugger \& Hoffmann 2004). Among heterotrophic bacteria, Bacteroidetes was the most abundant group. These bacteria are major utilizers of high-molecular-mass organic matter dissolved in marine ecosystems (Cottrell \& Kirchman 2000). Bacteroidetes were followed in abundance by Proteobacteria; interestingly, higher percentages of 2 orders belonging to these 2 phyla (Cytophagales and Sphingomonadales, respectively) characterized the subsample S3_2 that accidentally contained a barnacle recruit (Chthamalus sp.) (L. Bongiorni pers. obs.). This subsample was also the most diverse in terms of exclusive taxa. Although based on a single observation, this result is in agreement with past studies that have suggested that barnacles have positive effects on biofilm through the provision of favorable secondary habitat and amelioration of abiotic conditions (Thompson et al. 1996, Maggi et al. 2015). However, only more extensive studies on the diversity of epilithic microbial communities on rocky substrates will further elucidate such phenomena.

EMPB biomass showed no seasonal trend, but a peak in abundance occurred during the last 2 warm dates (Fig. 4). As previously mentioned, cold and warm dates were temporally segregated (i.e. cold dates sampled in 2012 and 2013, then warm ones in 2013 and 2014), so that possible seasonal variability within 2012 and 2014 could have been masked. However, lack of variability between cold and warm dates in 2013 reinforces our findings and conclusions. In addition, our results are in agreement with a recent study conducted along Australian rocky coasts, which showed no seasonal variation in EMPB biomass high on the shore (Jackson et al. 2010). In that case, lack of temporal variation was partially ascribed to the high resistance of dominating cyanobacteria to desiccation stress, which prevented the expected strong decrease in biomass during warmer periods. Interestingly, the same authors found a negative correlation between the amount of chl $a$ and maximum air temperature for the previous month (Jackson et al. 2010), and hypothesized that extreme events might be more important than average temperature conditions in influencing the amount of EMPB. This has been confirmed in a recent study conducted at the study site, which investigated the effects of warming extremes on EMPB (Dal Bello et al. 2017b). In our study, it is possible that the observed increase in biomass during the last summer period was associated with the lower average maximum air temperature recorded during the previous months (July-September 2014) when compared with the year before (July-September 2013) (mean $\pm 1 \mathrm{SE}$ : $26.3 \pm 0.17^{\circ} \mathrm{C}$ and $27.5 \pm 0.26^{\circ} \mathrm{C}$, respectively; data recorded at Livorno; www.mareografico.it).

The analysis highlighted a significant increase in spatial variance at scales ranging from a few centimeters to meters from the cold to warm season. Furthermore, variability was larger at small spatial scales compared with large spatial scales during warm months. In marine benthic systems, most of the variation in spatial patterns of abundance of macroorganisms has been observed at small scales (see Fraschetti et al. 2005 and references therein). This result suggested a key role for biotic interactions, as well as small-scale physical processes, in shaping marine habitats (Underwood \& Chapman 1996, Benedetti-Cecchi 2001). However, these findings might be contingent on the specific time at which the study was conducted and the comparison of spatial variances at different times is necessary to exclude the influence of temporally variable factors (Underwood \& Petraitis 1993). Our results highlight the importance of examining spatial and temporal variation simultaneously to correctly identify key scales of variability in the abundance of organisms. In fact, a previous study conducted on the same coast suggested scale-invariance in the spatial distribution of EMPB biomass (Dal Bello et al. 2015), apparently in contrast with our results. In this previous study, however, EMPB was sampled continuously over a few meters of substratum and in the cold season, so the results are not directly comparable to those obtained here. The significant interaction between temporal 
and spatial sources of variability identified in the present study might also emerge when considering variation continuously in space, which is worth testing in the future.

How can space-time interactions arise? In the system investigated in this study, small-scale topographic features, such as pits and crevices, could have provided more favorable habitats for EMPB during high desiccation stress, thus promoting heterogeneity in biomass distribution more during the warm months than the cold months. In addition, topography might have mediated the impact of biotic interactions, in particular, the grazing pressure exerted on biofilm by the littorinid snail Melaraphe neritoides (Stafford \& Davies 2005, Skov et al. 2010, Dal Bello et al. 2015). An increase in spatial variance of microphytobenthos at small scales has been related to grazing activity both on rocky shores and in soft sediments (Stafford \& Davies 2005, Como et al. 2014). On rocky habitats, littorinids are usually more active in moist conditions (Bates \& Hicks 2005), which mainly occur during rainy days or storm events high on the shore at our sites, due to the limited amplitude of tides (Benedetti-Cecchi et al. 2006, Dal Bello et al. 2017b). Under these conditions, which are more frequent during cold months than warm months, $M$. neritoides shows a relatively homogenous distribution. In contrast, during dry periods, littorinids show more aggregated patterns, which are commonly associated with the presence of relatively large pits or crevices (M. Dal Bello unpubl. data). This distribution pattern might have caused a significant concentration of grazing around patches of EMPB during warm months, thus enhancing smallscale spatial heterogeneity (Hawkins \& Hartnoll 1983, Stafford \& Davies 2005). Further research is needed to translate these speculative propositions into formal tests of hypotheses, by means of manipulative experiments. It is worth noting that grazers might also indirectly increase spatial variance in abundance of their resource by enhancing the mean biomass of the resource itself (Taylor 1961, Benedetti-Cecchi 2003, Benedetti-Cecchi et al. 2005). In this case, we can reasonably exclude such an effect, due to similar relationships between mean and variance of EMPB biomass at the different spatial scales analyzed (data not shown).

EMPB biomass also showed significant variability on a daily scale, in 2 out of 3 randomly selected sunny days. This new result emphasizes the possible role of daily acclimation behavior of biofilm on rock surfaces. In intertidal soft sediments, microphytobenthos (generally diatom dominated) exhibit rhythmic vertical migrations across the photic zone of the sediment, related to tidal and day-night cycles, usually moving downwards at high tide to intercept light and/or escape grazers and predators (Consalvey et al. 2004). In addition, at low tide under supersaturating light intensities, diatoms exhibit a negative phototaxis resulting in downward micro-migration (Perkins et al. 2010). From a physiological perspective, both diatoms and cyanobacteria can dissipate excess energy through non-photochemical quenching (NPQ) of chl a fluorescence (Bailey \& Grossman 2008, Perkins et al. 2010), as well as synthesize EPS substances, which are typically produced during emersion periods to protect them against desiccation and facilitate movement (Decho 1990, Potts 1999, Underwood \& Paterson 2003). What can observed changes in RVI on a daily scale tell us about physiological and behavioral responses of rocky shore EMPB to increasing irradiance or desiccation conditions? The decrease in RVI values could be partially due to an increased production of EPS as a defense against desiccation; in fact, EPS could have partially hindered the signal to the infrared-sensitive camera (which works on differential absorption of light), thus underestimating EMPB biomass during the most stressful hours. A copious polymeric matrix has been observed in samples collected on tropical rocky shores dominated by filamentous cyanobacteria on splash zone substrata in the Gulf of Mexico (OrtegaMorales et al. 2005). The lack of extensive visible EPS sheaths or slime in our SEM samples could be due to their collection early in the morning. In addition, our results could be explained by the capacity of EMPB to move and shelter within microscopic spaces following an increase in light intensity and/or desiccation stress from the morning until the early afternoon. Although the vertical migration range in rock substrata is apparently limited, rock surfaces are subjected to erosive mechanisms, such as weathering processes and activity of boring organisms (including cyanobacteria), which can create superficial holes or crevices of variable, microscopic size (Golubic 1969, Naylor et al. 2012, Pappalardo et al. 2016, Fig. 5 in this study). These hypotheses were supported by the particularly evident decrease in RVI values on 11 May 2012, when the average air temperature was relatively high, especially compared with the other 2 sampling days. It is worth noting here that changes in fluorescence due to NPQ could not have affected RVI values, which are based on absorbance of light by chl a pigments.

Variability in EMPB daily patterns observed among sampling days deserves further attention and investi- 
gation, as well as temporal replication under a wider range of weather and climate conditions. This will allow us to disentangle possible key factors inducing active movement of cyanobacteria-dominated biofilms (e.g. variation in air or rock temperature, UV radiation, light intensity as well as micro-topography of the rock surface) from physiological adaptations due to EPS synthesis.

Our analysis has identified seasonal differences in the relevant spatial scales of the distribution of EMPB biomass, suggesting complex interactions among stressful abiotic conditions, topography of the substratum and grazing activity. These interactions are likely to occur in other marine benthic systems exposed to large fluctuations in physical and biological processes, emphasizing the importance of examining ecological patterns in space and time simultaneously to uncover complex patterns and processes. Our results also highlighted the potential for daily variation in EMPB biomass, suggesting for the first time that cyanobacteria living high on the rocky shore might cope with stressful environmental conditions through both physiological and behavioral adaptation strategies. This novel hypothesis stresses the need for additional research on the ecology and physiology of rocky shore microorganisms, to better understand their network of interactions and their role as primary producers.

Acknowledgements. We thank Dr. A. C. Jackson for invaluable help with fine-tuning the sampling methodology with the ADC camera.

\section{LITERATURE CITED}

Bailey S, Grossman A (2008) Photoprotection in cyanobacteria: regulation of light harvesting. Photochem Photobiol 84:1410-1420

Bates TW, Hicks DW (2005) Locomotory behavior and habitat selection in littoral gastropods on Caribbean limestone shores. J Shellfish Res 24:75-84

Benedetti-Cecchi L (2001) Variability in abundance of algae and invertebrates at different spatial scales on rocky sea shores. Mar Ecol Prog Ser 215:79-92

Benedetti-Cecchi L (2003) The importance of the variance around the mean effect size of ecological processes. Ecology 84:2335-2346

Benedetti-Cecchi L, Vaselli S, Maggi E, Bertocci I (2005) Interactive effects of spatial variance and mean intensity of grazing on algal cover in rockpools. Ecology 86: 2212-2222

Benedetti-Cecchi L, Bertocci I, Vaselli S, Maggi E (2006) Temporal variance reverses the impact of high mean intensity of stress in climate change experiments. Ecology 87:2489-2499

B Blanchette CA, Broitman BR, Gaines SD (2006) Intertidal community structure and oceanographic patterns around Santa Cruz Island, CA, USA. Mar Biol 149:689-701
Broitman BR, Kinlan BP (2006) Spatial scales of benthic and pelagic producer biomass in a coastal upwelling ecosystem. Mar Ecol Prog Ser 327:15-25

* Burrows MT, Harvey R, Robb L, Poloczanska ES and others (2009) Spatial scales of variance in abundance of intertidal species: effects of region, dispersal mode, and trophic level. Ecology 90:1242-1254

Caporaso JG, Kuczynski J, Stombaugh J, Bittinger K and others (2010) QIIME allows analysis of high-throughput community sequencing data. Nat Methods 7:335-336

* Caporaso JG, Lauber CL, Walters WA, Berg-Lyons D and others (2012) Ultra-high-throughput microbial community analysis on the Illumina HiSeq and MiSeq platforms. ISME J 6:1621-1624

Castenholz RW (1963) An experimental study of the vertical distribution of littoral marine diatoms. Limnol Oceangr 8: 450-462

* Christofoletti RA, Almeida TVV, Ciotti AM (2011) Environmental and grazing influence on spatial variability of intertidal biofilm on subtropical rocky shores. Mar Ecol Prog Ser 424:15-23

* Claesson MJ, O'Sullivan O, Wang Q, Nikkila J and others (2009) Comparative analysis of pyrosequencing and a phylogenetic microarray for exploring microbial community structures in the human distal intestine. PLOS ONE 4:e6669

* Como S, Lefrancois C, Maggi E, Antognarelli F, Dupuy C (2014) Behavioral responses of juvenile golden gray mullet Liza aurata to changes in coastal temperatures and consequences for benthic food resources. J Sea Res 92:66-73

Consalvey M, Paterson DM, Underwood GJC (2004) The ups and downs of life in a benthic biofilm: migration of benthic diatoms. Diatom Res 19:181-202

Cottrell MT, Kirchman DL (2000) Natural assemblages of marine proteobacteria and members of the CytophagaFlavobacter cluster consuming low- and high-molecularweight dissolved organic matter. Appl Environ Microbiol 66:1692-1697

* Dal Bello M, Maggi E, Rindi L, Capocchi A, Fontanini D, Sanz-Lazaro C, Benedetti-Cecchi L (2015) Multifractal spatial distribution of epilithic microphytobenthos on a Mediterranean rocky shore. Oikos 124:477-485

*Dal Bello M, Leclerc J-C, Benedetti-Cecchi L, Andrea De Lucia G and others (2017a) Consistent patterns of spatial variability between NE Atlantic and Mediterranean rocky shores. J Mar Biol Assoc UK 97:539-547

* Dal Bello M, Rindi L, Benedetti-Cecchi L (2017b) Legacy effects and memory loss: how contingencies moderate the response of rocky intertidal biofilms to present and past extreme events. Glob Change Biol 23:3259-3268

Decho AW (1990) Microbial exopolymer secretions in ocean environments: their role(s) in food webs and marine processes. Oceanogr Mar Biol Annu Rev 28:73-153

DeSantis TZ, Hugenholtz P, Larsen N, Rojas M and others (2006) Greengenes, a chimera-checked 16S rRNA gene database and workbench compatible with ARB. Appl Environ Microbiol 72:5069-5072

* Dye AH, White DRA (1991) Intertidal microalgal production and molluscan herbivory in relation to season and elevation on two rocky shores on the east coast of southern Africa. S Afr J Mar Sci 11:483-489

*Edgar RC (2010) Search and clustering orders of magnitude faster than BLAST. Bioinformatics 26:2460-2461

Egeland ES (2011) Specific absorption coefficients for major algal chlorophylls, bacteriochlorophylls and carotenoids. Electronic published supplement to Roy S, Llewellyn CA, 
Egeland ES, Johnsen G (eds) Phytoplankton pigments: characterization, chemotaxonomy and applications in oceanography. Cambridge University Press, Cambridge. www.cambridge.org/phytoplankton

Fraschetti S, Terlizzi A, Benedetti-Cecchi L (2005) Patterns of distribution of marine assemblages from rocky shores: evidence of relevant scales of variation. Mar Ecol Prog Ser 296:13-29

Golubic S (1969) Distribution, taxonomy, and boring patterns of marine endolithic algae. Am Zool 9:747-751

Gugger MF, Hoffmann L (2004) Polyphyly of true branching cyanobacteria (Stigonematales). Int J Syst Evol Microbiol 54:349-357

*Haas BJ, Gevers D, Earl AM, Feldgarden M and others (2011) Chimeric 16S rRNA sequence formation and detection in Sanger and 454-pyrosequenced PCR amplicons. Genome Res 21:494-504

Hill AS, Hawkins SJ (1991) Seasonal and spatial variation of epilithic microalgal distribution and abundance and its ingestion by Patella vulgata on a moderately exposed rocky shore. J Mar Biol Assoc UK 71:403-423

*Huang SY, Hadfield MG (2003) Composition and density of bacterial biofilms determine larval settlement of the polychaete Hydroides elegans. Mar Ecol Prog Ser 260: 161-172

*Jackson AC, Underwood AJ, Murphy RJ, Skilleter GA (2010) Latitudinal and environmental patterns in abundance and composition of epilithic microphytobenthos. Mar Ecol Prog Ser 417:27-38

Jenkins SR, Hartnoll RG (2001) Food supply, grazing activity and growth rate in the limpet Patella vulgata L.: a comparison between exposed and sheltered shores. J Exp Mar Biol Ecol 258:123-139

Jenkins SR, Åberg P, Cervin G, Coleman RA and others (2000) Spatial and temporal variation in settlement and recruitment of the intertidal barnacle Semibalanus balanoides (L.) (Crustacea: Cirripedia) over a European scale. J Exp Mar Biol Ecol 243:209-225

LaScala-Gruenewald DE, Miller LP, Bracken MES, Allen BJ, Denny MW (2016) Quantifying the top-down effects of grazers on a rocky shore: selective grazing and the potential for competition. Mar Ecol Prog Ser 553:49-66

Lozupone C, Knight R (2005) UniFrac: a new phylogenetic method for comparing microbial communities. Appl Environ Microbiol 71:8228-8235

Kozupone C, Hamady M, Knight R (2006) UniFrac-an online tool for comparing microbial community diversity in a phylogenetic context. BMC Bioinformatics 7:371

* Magalhães C, Bano N, Wiebe WJ, Hollibaugh JT, Bordalo AA (2007) Composition and activity of beta-Proteobacteria ammonia-oxidizing communities associated with intertidal rocky biofilms and sediments of the Douro River estuary, Portugal. J Appl Microbiol 103:1239-1250

Maggi E, Milazzo M, Graziano M, Chemello R, BenedettiCecchi L (2015) Latitudinal- and local-scale variations in a rocky intertidal interaction web. Mar Ecol Prog Ser 534: 39-48

* Martins GM, Thompson RC, Hawkins SJ, Neto AI, Jenkins SR (2008) Rocky intertidal community structure in oceanic islands: scales of spatial variability. Mar Ecol Prog Ser 356:15-24

Menconi M, Benedetti-Cecchi L, Cinelli F (1999) Spatial and temporal variability in the distribution of algae and invertebrates on rocky shores in the northwest Mediterranean. J Exp Mar Biol Ecol 233:1-23

Nagarkar S, Williams GA (1999) Spatial and temporal variation of cyanobacteria-dominated epilithic communities on a tropical shore in Hong Kong. Phycologia 38:385-393

Naylor LA, Coombes MA, Viles HA (2012) Reconceptualising the role of organisms in the erosion of rock coasts: a new model. Geomorphology 157-158:17-30

${ }^{\prime} O^{\prime}$ Connor NJ, Richardson DL (1998) Attachment of barnacle (Balanus amphitrite Darwin) larvae: responses to bacterial films and extracellular materials. J Exp Mar Biol Ecol 226:115-129

* Ortega-Morales BO, Santiago-Garcia JL, Lopez-Cortes A (2005) Biomass and taxonomic richness of epilithic cyanobacteria in a tropical intertidal rocky habitat. Bot Mar 48:116-121

*Pappalardo M, Buehler M, Chelli A, Cironi L, Pannacciulli F, Qin Z (2016) Quantitative estimates of bio-remodeling on coastal rock surfaces. J Mar Sci Eng 4:37

* Perkins RG, Lavaud J, Serodio J, Mouget JL and others (2010) Vertical cell movement is a primary response of intertidal benthic biofilms to increasing light dose. Mar Ecol Prog Ser 416:93-103

* Potts M (1999) Mechanisms of desiccation tolerance in cyanobacteria. Eur J Phycol 34:319-328

R Development Core Team (2013) R: a language and environment for statistical computing, version 2.15.3. R Foundation for Statistical Computing, Vienna

*Rideout JR, He Y, Navas-Molina JA, Walters WA and others (2014) Subsampled open-reference clustering creates consistent, comprehensive OTU definitions and scales to billions of sequences. PeerJ 2:e545

Sanz-Lázaro C, Rindi L, Maggi E, Dal Bello M, BenedettiCecchi L (2015) Effects of grazer diversity on marine microphytobenthic biofilm: a 'tug of war' between complementarity and competition. Mar Ecol Prog Ser 540: 145-155

Singer JD, Willet JB (2003) Applied longitudinal data analysis. Oxford University Press, New York, NY

Skov MW, Volkelt-Igoe M, Hawkins SJ, Jesus B, Thompson RC, Doncaster CP (2010) Past and present grazing boosts the photo-autotrophic biomass of biofilms. Mar Ecol Prog Ser 401:101-111

* Smith DJ, Underwood GJC (1998) Exopolymer production by intertidal epipelic diatoms. Limnol Oceanogr 43: 1578-1591

Stafford R, Davies MS (2005) Spatial patchiness of epilithic biofilm caused by refuge-inhabiting high shore gastropods. Hydrobiologia 545:279-287

Taylor LR (1961) Aggregation, variance, and the mean. Nature 189:732-735

Taylor JD, Ellis R, Milazzo M, Hall-Spencer JM, Cunliffe M (2014) Intertidal epilithic bacteria diversity changes along a naturally occurring carbon dioxide and $\mathrm{pH}$ gradient. FEMS Microbiol Ecol 89:670-678

* Thompson RC, Wilson BJ, Tobin ML, Hill AS, Hawkins SJ (1996) Biologically generated habitat provision and diversity of rocky shore organisms at a hierarchy of spatial scales. J Exp Mar Biol Ecol 202:73-84

* Thompson RC, Roberts MF, Norton TA, Hawkins SJ (2000) Feast or famine for intertidal grazing molluscs: a mismatch between seasonal variations in grazing intensity and the abundance of microbial resources. Hydrobiologia 440:357-367

* Thompson RC, Norton TA, Hawkins SJ (2004) Physical stress and biological control regulate the producerconsumer balance in intertidal biofilms. Ecology 85: 1372-1382

* Thompson RC, Moschella PS, Jenkins SR, Norton TA, Hawkins SJ (2005) Differences in photosynthetic marine biofilms between sheltered and moderately exposed 
rocky shores. Mar Ecol Prog Ser 296:53-63

Underwood AJ (1978) An experimental evaluation of competition between three species of intertidal prosobranch gastropods. Oecologia 33:185-202

Underwood AJ (1984) Vertical and seasonal patterns in competition for microalgae between intertidal gastropods. Oecologia 64:211-222

Underwood AJ (1997) Experiments in ecology. Oxford University Press, Oxford

Underwood AJ, Chapman MG (1996) Scales of spatial patterns of distribution of intertidal invertebrates. Oecologia 107:212-224

Underwood AJ, Petraitis PS (1993) Structure of intertidal assemblages in different locations: How can local processes be compared? In: Ricklefs RE, Schluter D (eds) Species diversity in ecological communities. University of Chicago, Chicago, IL, p 38-51

Underwood GJC, Paterson DM (2003) The importance

Editorial responsibility: Peter Steinberg,

Sydney, New South Wales, Australia of extracellular carbohydrate production by marine epipelic diatoms. Adv Bot Res 40:183-240

* Underwood GJC, Paterson DM, Parkes RJ (1995) The measurement of microbial carbohydrate exopolymers from intertidal sediments. Limnol Oceanogr 40:1243-1253

*Van Heukelem L, Thomas CS (2001) Computer-assisted high-performance liquid chromatography method development with applications to the isolation and analysis of phytoplankton pigments. J Chromatogr A 910:31-49

*Vázquez-Baeza Y, Pirrung M, Gonzalez A, Knight R (2013) EMPeror: a tool for visualizing high-throughput microbial community data. Gigascience 2:16

*Williams GA, Davies MS, Nagarkar S (2000) Primary succession on a seasonal tropical rocky shore: the relative roles of spatial heterogeneity and herbivory. Mar Ecol Prog Ser 203:81-94

Winer BJ (1971) Statistical principles in experimental designs. McGraw-Hill, New York, NY

Submitted: December 13, 2016; Accepted: May 31, 2017

Proofs received from author(s): July 8, 2017 